\title{
Light and electron microscope evidence of baculovirus infection in the prawn Penaeus plebejus
}

\author{
R. J. G. Lester ${ }^{1}$, A. Doubrovsky ${ }^{2}$, J. L. Paynter ${ }^{1}$, S. K. Sambhi' ${ }^{2}$, J. G. Atherton ${ }^{2}$ \\ ${ }^{1}$ Department of Parasitology, University of Queensland, Brisbane, 4067 Australia \\ ${ }^{2}$ Department of Microbiology, University of Queensland, Brisbane, 4067 Australia
}

\begin{abstract}
A baculovirus of Penaeus plebejus for which we propose the name Plebejus Baculovirus (PBV) was found in postlarval and juvenile P. plebejus from a hatchery and grow-out pond in New South Wales, Australia. Subspherical eosinophilic inclusion bodies, mostly single or in pairs, were in hypertrophied nuclei of the hepatopancreas and mid-gut epithelial cells. Electron microscopy revealed a crystalline lattice of periodicity $20 \mathrm{~nm}$ in the inclusion bodies. Virions up to $440 \mathrm{~nm}$ long, both free and occluded in the inclusion body, were scattered in the nuclei. The capsid envelope contained 2 electrondense layers
\end{abstract}

\section{INTRODUCTION}

The development of prawn aquaculture has led to the discovery of 6 prawn viruses (Lightner et al. 1986), all of which increase mortality rates in cultured prawns. Three of the 6 are baculoviruses. Baculovirus penaei (BP), the first to be described (Couch 1974) has been reported from 6 penaeid species, Penaeus vannamei, $P$. stylirostris, $P$. setiferus, $P$. aztecus, $P$. duorarum and $P$. marginatus. Its tetrahedral inclusion bodies are found in the nuclei of the hepatopancreas (digestive gland). Baculoviral mid-gut gland necrosis virus (BMN) has been reported only from the hepatopancreas of $P$. japonicus. It does not produce inclusion bodies. The $P$. monodon baculovirus, MBV, produces spherical intranuclear inclusion bodies in the hepatopancreas of 3 hosts, $P$. monodon, $P$. merguiensis and P. semisulcatus (Lightner et al. 1986).

During our work on diseases of cultured prawns we came across a fourth baculovirus, details of which are presented below. It was brought to our attention by $\mathrm{Mr}$ Imamura of Japan who on visiting a hatchery in New South Wales, Australia, noticed that many post-larvae had cloudy digestive glands similar to post-larval prawns infected with BMN. The baculovirus we found is described below, and we propose for it the name Plebejus Baculovirus (PBV). It is the first baculovirus to be found in an Australian penaeid. One other penaeid virus has so far been reported from Australia; hepatopancreatic parvo-like virus (HPV) in Penaeus esculentus (Paynter et al. 1985).

\section{MATERIALS AND METHODS}

Three lots of infected prawns Penaeus plebejus were examined. All had been raised in a hatchery in northern New South Wales from brood stock caught off the New South Wales coast. Those in the first 2 groups were post-larvae (PL 4 to PL 8) taken in March 1987 from indoor tanks. Those in the third group were juveniles, 3 to $4 \mathrm{~g}$, taken from grow-out ponds in April 1987. Tissues for light microscopy were fixed in Davidson's fixative (Humason 1972) and sectioned at $3 \mu \mathrm{m}$. Those for electron microscopy were fixed in $2.5 \%$ glutaraldehyde in $0.1 \mathrm{M}$ sodium cacodylate buffer for $4 \mathrm{~h}$, postfixed in osmium tetroxide, and embedded in LR White (S. P. C. Diagnostics Pty Ltd, Melbourne) at $60^{\circ} \mathrm{C}$ for $24 \mathrm{~h}$ prior to sectioning.

\section{RESULTS}

The epithelium of the hepatopancreas of prawns in all groups contained cells with subspherical intranuclear inclusion bodies (Fig. 1). These occurred singly in 

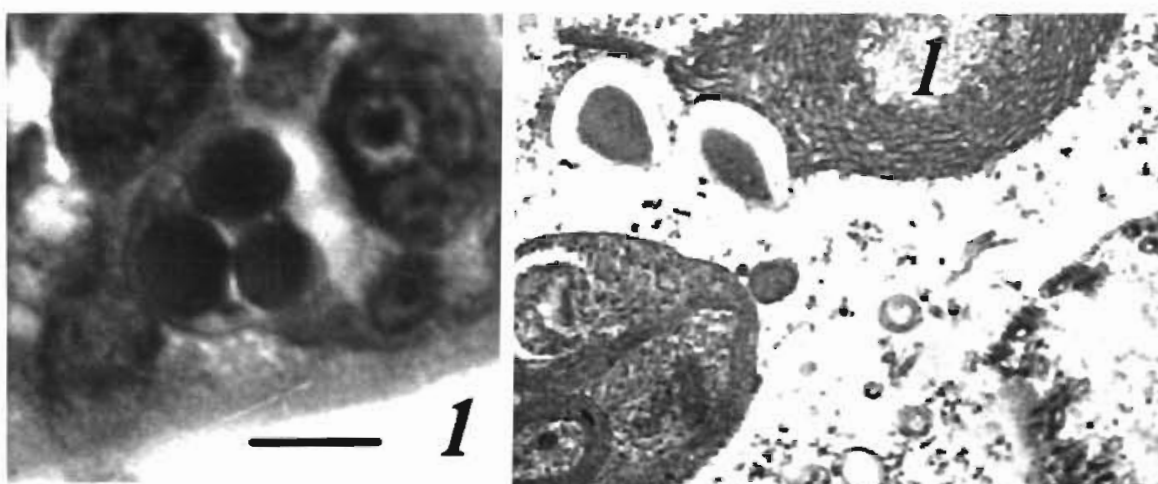

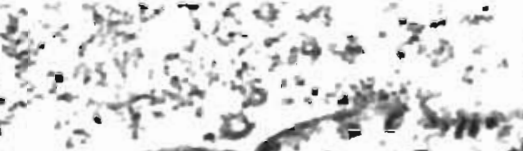

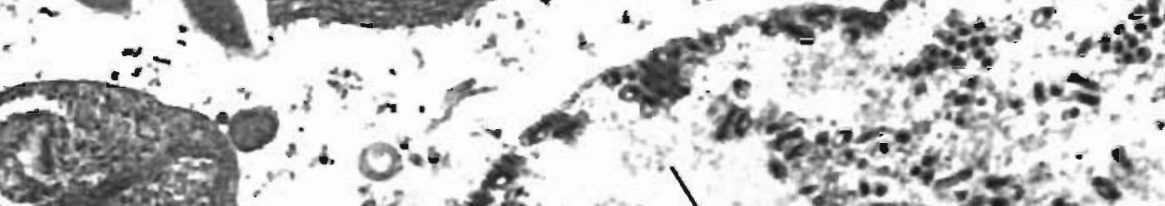

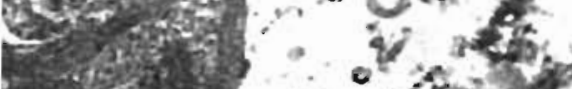

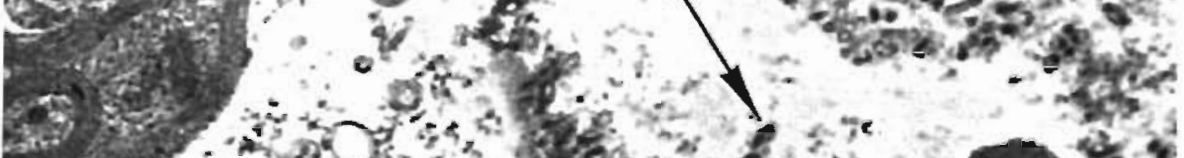

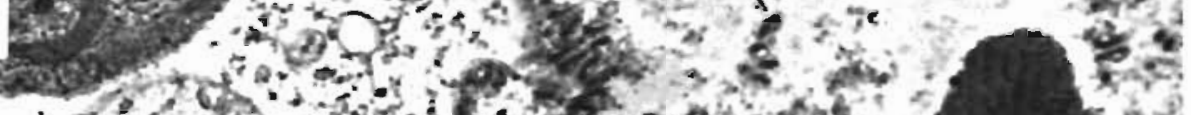

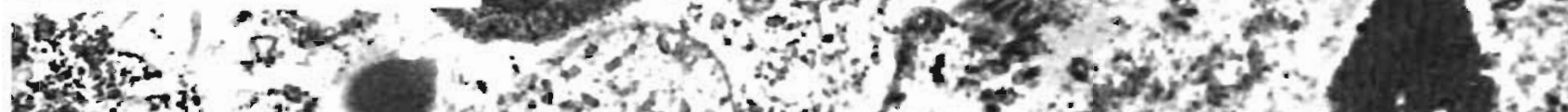
6)

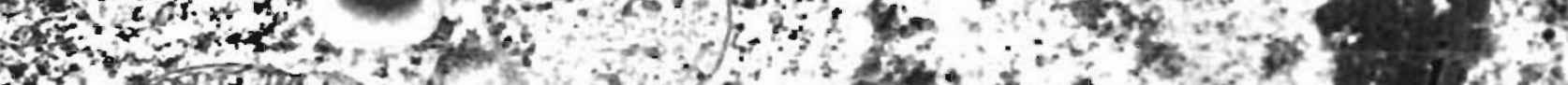

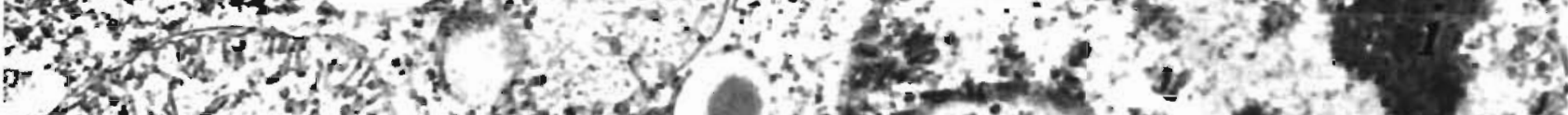

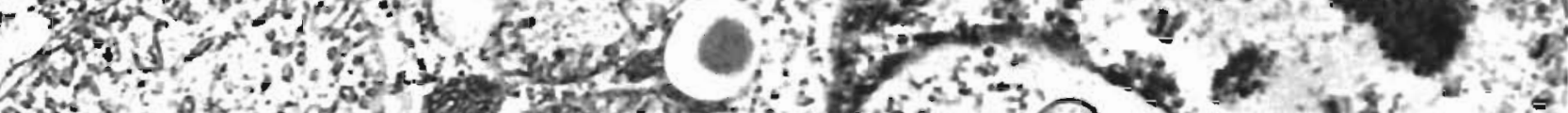
6.5.

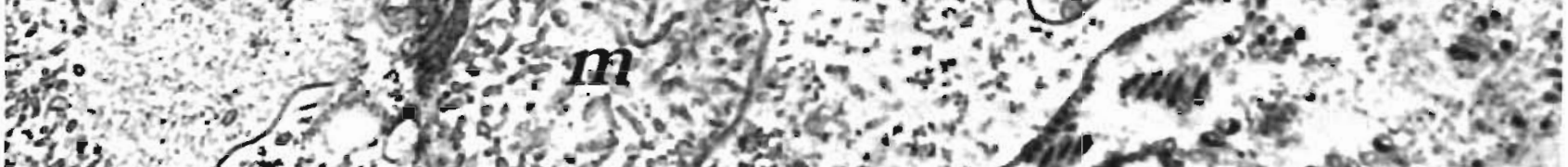

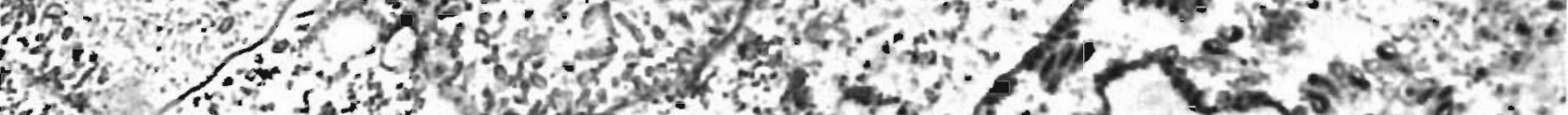

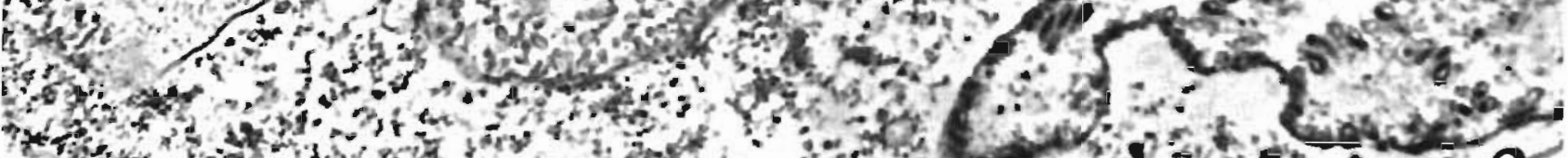

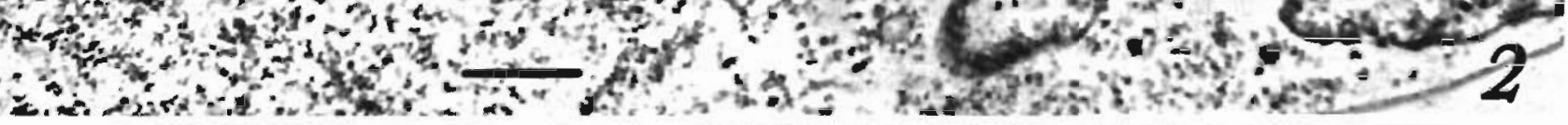
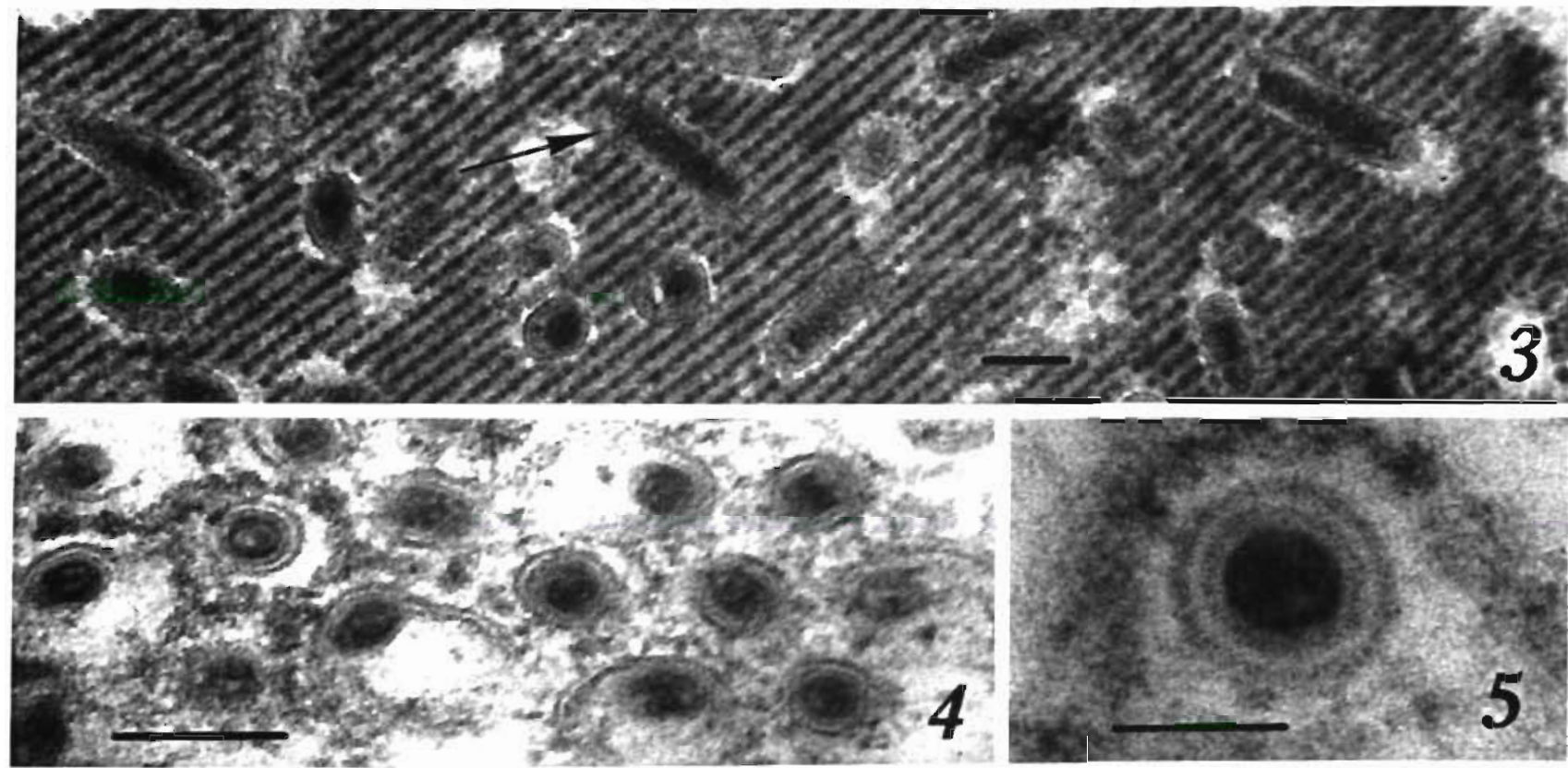

Figs. 1 to 5. Penaeus plebejus. Fig. 1. Light micrograph of epithelium of hepatopancreatic tubule showing an infected cell containing 3 intranuclear inclusion bodies; haematoxylin and eosin; bar $=10 \mathrm{~mm}$. Fig. 2. Electron micrograph of infected cell showing inclusion body (i), mitochondria $(\mathrm{m})$, membranous labyrinth (l) and virions (arrow); bar $=1$ um. Fig. 3 . Crystalline lattice of an inclusion body showing occluded virions (arrow); bar $=100 \mathrm{~nm}$. Fig. 4. Cross-sections of non-occluded virions showing the envelope in close apposition to and free from the nucleocapsid; bar $=100 \mathrm{~nm}$. Fig. 5. Cross-section of virion showing the 2 
more than half of the affected cells, and in multiples in the others. Few cells had more than 3; one cell had 9 (spread over 2 sections). Nuclei with multiple bodies were slightly more abundant in the post-larvae than in the juveniles. Inclusions were strongly eosinophilic, stained variably with Giemsa and PAS, were pale with Feulgen's stain, and were Gram negative with Brown and Brenn's Gram stain. Infected nuclei were greatly enlarged.

Ultrastructurally, the cytoplasm of heavily infected cells contained one or more membranous labyrinths, little intact endoplasmic reticulum, and apparently normal mitochondria (Fig. 2). In some cells the 2 unit membranes of the nuclear membrane had separated and had large gaps.

Within the nucleus was a prominent inclusion body. It had a crystalline lattice of periodicity $20 \mathrm{~nm}$ (Fig. 3). In some cells the lattice was oriented in different planes in different parts of the same inclusion. A fibrous stroma was occasionally seen within and outside inclusions. Virions up to $440 \mathrm{~nm}$ long, both free and occluded in the inclusion body, were scattered within the nucleus (Figs. 2, 3 and 4). Many lined the inner surface of the nuclear membrane. The envelope of some non-occluded virions was detached from the nucleocapsid for part of its length (Figs. 2 and 4). The envelope was composed of 2 electron-dense layers (Figs. 3,4 and 5). The nucleocapsid, diameter 30 to $45 \mathrm{~nm}$, had an electron-dense core and an electronlucent margin.

Of the postlarvae, $80 \%$ in the infected batch died. It is not clear whether or not this was entirely due to the virus as the hatchery had water quality, nutritional and density problems at the time the virus was detected.

\section{DISCUSSION}

The new virus, PBV, is a type A baculovirus since it has a rod-shaped, enveloped nucleocapsid, many of which are occluded in an intranuclear inclusion body. Of the 2 penaeid type A baculoviruses already reported, it is clearly distinct from Baculovirus penaei (BP) as the latter has tetrahedral inclusion bodies. It resembles the Monodon baculovirus (MBV) in that both have round inclusion bodies. However in PBV over half the affected cells contained only one inclusion body; in MBV the bodies develop as multiples (Lightner et al. 1983). The PBV body is strongly and uniformly eosinophilic; MBV inclusion bodies are weakly eosinophilic at their periphery and almost unstained at the centre. PBV bodies are Gram negative; MBV bodies stain 'intensely' with Brown and Brenn according to Lightner \& Redman (1981) and from their Fig, 1 appear to be Gram positive.

Ultrastructurally, the virion of PBV differs from MBV in the appearance of the capsid envelope; the envelope of PBV has 2 electron-dense zones, MBV has only one. The dimensions of the virions of the 2 viruses are similar. The PBV virion is up to $440 \mathrm{~nm}$ long (vs $420 \mathrm{~nm}$ for MBV), $60 \mathrm{~nm}$ in diameter (vs 64 to $87 \mathrm{~nm}$ for MBV), and the nucleocapsid diameter is 30 to $45 \mathrm{~nm}$ (vs 37 to $46 \mathrm{~nm}$ in Lightner et al. 1983, and $24 \pm 5 \mathrm{~nm}$ in Lightner \& Redman 1981). The periodicity of the crystalline lattice is $20 \mathrm{~nm}$ (vs 26 to $27 \mathrm{~nm}$ for MBV).

Lightner et al. (1986) reported MBV or MBV-like infections from 3, possibly 4, penaeid species from widely separated geographical locations. They suggested that the viruses causing these infections could represent a complex of viruses. The many differences between PBV and MBV indicate that it is unlikely PBV is a strain of MBV. We plan to expose Penaeus monodon to PBV and if infections develop, will examine infected cells histologically and ultrastructurally to confirm that the characteristics of PBV are consistent between these prawn species.

Acknowledgements. We thank Mr R. Webb for guidance in EM techniques. The project was supported financially by the Fishing Industry Research Trust Account and the Rural Credits Development Fund.

\section{LITERATURE CITED}

Couch, J. A. (1974). An enzootic nuclear polyhedrosis virus of pink shrimp: ultrastructure, prevalence, and enhancement. J. Invert. Pathol. 24: 311-331

Lightner, D. V., Redman, R. M. (1981). A baculovirus-caused disease of the penaeid shrimp, Penaeus monodon. J. Invert. Pathol. 38: 299-302

Lightner, D. V., Redman, R. M., Bell, T A. (1983). Observations on the geographic distribution, pathogenesis and morphology of the baculovirus from Penaeus monodon Fabricius. Aquaculture 32: 209-233

Lightner, D. V., Redman, R. M., Williams, R. R., Mohney, L. L., Clerx, J. P. M., Bell, T. A. (1986). Recent advances in penaeid virus disease investigations. World Mar. Soc. 16: $267-275$

Humason, G. L. (1972). Animal tissue techniques, 3rd edn. Freeman, San Francisco

Paynter, J. L., Lightner, D. V., Lester, R. J. G. (1985). Prawn virus from juvenile Penaeus esculentus. In: Rothlisberg, P. C., Hill, B. J., Staples, D. J. (eds.) Second Australian National Prawn Seminar. NPS2, Cleveland, Australia, p. $61-6$ 